\title{
SOSE-Based E-Government Systems: A Systematic Literature Review
}

\author{
Musa Midila Ahmed \\ Faculty of Education, Department of Physical Science Education, Modibbo Adama \\ University, Yola, Nigeria \\ OrcidID: 0000-0002-7769-6400; E-mail: ahmedmm4me@yahoo.com
}

Area/Section: Education.

Type of the Paper: Literature Review.

Type of Review: Peer Reviewed as per $|\mathrm{C}| \mathrm{O}|\mathrm{P}| \mathrm{E} \mid$ guidance.

Indexed in: OpenAIRE.

DOI: https://doi.org/10.5281/zenodo.5807721

Google Scholar Citation: IJMTS

\section{How to Cite this Paper:}

Ahmed, Musa Midila, (2021). SOSE-Based E-Government Systems: A Systematic Literature Review. International Journal of Management, Technology, and Social Sciences (IJMTS), 6(2), 282-295. DOI: https://doi.org/10.5281/zenodo.5807721

International Journal of Management, Technology, and Social Sciences (IJMTS)

A Refereed International Journal of Srinivas University, India.

CrossRef DOI: https://doi.org/10.47992/IJMTS.2581.6012.0171

(C) With Author.

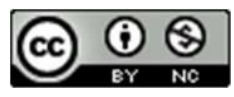

This work is licensed under a Creative Commons Attribution-Non-Commercial 4.0 International License subject to proper citation to the publication source of the work.

Disclaimer: The scholarly papers as reviewed and published by the Srinivas Publications (S.P.), India are the views and opinions of their respective authors and are not the views or opinions of the SP. The SP disclaims of any harm or loss caused due to the published content to any party. 


\title{
SOSE-Based E-Government Systems: A Systematic Literature Review
}

\author{
Musa Midila Ahmed \\ Faculty of Education, Department of Physical Science Education, Modibbo Adama \\ University, Yola, Nigeria \\ OrcidID: 0000-0002-7769-6400; E-mail: ahmedmm4me@yahoo.com
}

\begin{abstract}
Purpose: E-government is a means of providing services by facilitating communication between government and citizens, government and businesses and among levels of government in a robust, flexible and efficient manner. Service-Oriented Software Engineering (SOSE) is a recognized approach of developing robust, flexible and efficient E-government system by transformation of existing systems. However, several challenges and issues in SOSE-Based Egovernment systems need to be addressed to attend the desired goal. This paper used systematic literature review (SLR) to identify, classify and analyze primary studies published in the research community from 2010 to 2021 that focused on SOSE approach for E-government systems.
\end{abstract}

Methodology/Approach: A review protocol was applied to gather 61 relevant primary studies that were critically analyzed, classified and evaluated.

Findings/Result: The results shows that research was active on this topic within the reviewed period. The review's record shows that the highest number of publication of 10 was in 2010 and lowest number of publication of 2 was in 2016. Furthermore, interoperability received the highest attention by researchers with 22 publications, whereas security received the lowest attention with 2 publications in the reviewed period. It is recommended that further research be conducted on modelling in view of the heterogeneous and dynamic nature of business operations in governance. In addition, further research is required toward SOSE security for protection of E-government systems.

Originality/Value: A new research direction identified on SOSE-Based E-Government System Paper Type: Review Research Paper.

Keywords: Systematic Literature Review, E-government, Digital Government, SOA-Based E-Government, SOSE-Based E-government

\section{INTRODUCTION :}

E-government refers to the application of information and communication technology (ICT) to enhance public service provision. E-government is a service delivery within governments as well as between governments and the public. Traditionally, government services are provided by ministries, departments and agencies (MDA) spread in different geographical locations using paper forms. Nowadays, digital service provision is prioritized by governments worldwide. The transition toward digital approach to public services by E-government service solution is advancing in the developed and developing world. For instance, the governments' digital service transformation worldwide is toward local governments offer services completely online [1]. The use of internet for government services and information is popular in America. Most Americans citizens interact with government by online channels. However, this is not evenly distributed across income and educational levels of citizens. A study by Lenhart, et al. [2] revealed that well-educated internet users and high-income earners are much more engaged than those on the lower levels. According to the author, majority of Americans prefer E-government and most online E-government interactions are successful.

E-government is define by Behara, et al. [3] as the use of modern technology to enhance the efficiency and effectiveness of service delivery as well as promote transparency among citizens. The recent popularity of the internet have modified the way people interact, learn, and work in most organizations including government service delivery [4]. The global revolution by use of internet naturally should 
transform the way government organizations provide services to its citizen, business and other government agencies [5]. E-government is the use of ICT to enhance information exchange between government and citizens, G2C, government and business, G2B as well as among governments G2G. In other word, E-government implementation promotes information sharing between government sectors $(\mathrm{G} 2 \mathrm{G})$, internal relationship between government and citizens $(\mathrm{G} 2 \mathrm{C})$ as well as integration of business applications to support governance (G2B). The aim of E-government is to enhance service delivery in such a way that citizens can easily interact and transparently participate in governance.

E-government is generally regarded as an approach for supporting government services to satisfy citizens with enhanced service performance, interoperability and security [6]. According to Alshomrani \& Qamar [7], the efficiency and effectiveness of utilization of ICT for public service provision worldwide leads to the concepts of e-business and e-commerce to the evolution of SOA. SOA establishes seamless, flexible, interoperable and autonomous services that runs online to support the business functions of e-governments. E-government has identical characteristics worldwide. However, it is complicated in some countries due to the complexity of multi-tier nature of their governance structure. This coupled with the diversity and autonomy of various ministries, departments and agencies of government [8]. Consequently, despite the huge investment made in ICT by governments worldwide, government operations still remain inefficient and ineffective. Therefore, further research is needed to provide more technologies, models and architectural tools for enhancing the administrations of Egovernment systems.

Despite the recognition of SOSE as a means of providing transparent, interoperable and efficient system by integrating heterogeneous services into distributed E-government system. However, high cost of SOSE's middleware and associated tools is a major bottleneck for adoption of the architecture. Although, Das, et al. [9] proposed the use open sources SOSE middleware tools for implementation of E-government. The author recommends Apache ServiceMix, Mulesource Mule, WSO2 ESB and JBoss ESB. Others are jitterbit and OpenAdapter open source ESB middleware for E-government implementation. Alghamdi, et al. [10] examined the best practice for a successful SOSE E-government by a critical success framework. The authors adopted qualitative research method by survey using semistructured interview of senior managers of Saudi Arabia's E-government programme. The study discovered that additional effort is needed for success in SOSE E-government adoption. The purpose of his study is to identify and synthesize relevant scholarly literature on SOSE-based E-government system as well as to provide further research direction. The remaining part of the paper is organized as follows; section 2 reviews related studies on SOSE-based E-government system as well as discusses on the research method and section 3 provides the results of the literature review. Section 4 is for conclusion and recommendation for further research.

\section{MATERIAL AND METHODS :}

\subsection{Related Works}

Analysis of the literatures in the reviewed period is broadly classified into four (4) categories; interoperability, integration, modelling and security. Interoperability in this context refers to the ability of different governments, organizations and businesses' information system connect and interact with each other to function effectively. Whereas integration is the amalgamation of isolated data for easy information sharing. Modelling is the systematic representation of a real world phenomenon in a plan to develop an E-government system. Finally, security hereby refers to the protection of E-government system against danger or threats. Although an overlap exist where studies investigated both integration and interoperability ([11]; [8]; [12]; [13]; [14]). First, Sedek, et al. [11] and El Benany, and El Beqqali, [8] considered both integration and interoperability as essential parameters for one-stop E-government portal. Second, Madouk \& Baraka [12] build SOA-based framework for Palestinian E-government that integrated central database to achieve interoperability. Third, Paul and Paul [13] attempts to achieve both integration and interoperability by enterprise architecture and SOA for E-government systems. Lastly, Alhajri, et al. [14] uses web service architecture to achieve integration and interoperability. The authors proposed an SOA-based framework for E-government integrated portal.

\section{a) Interoperability:}

Sedek, et al. [15] summarized existing literature on interoperability of E-government portal and discovered that most e-government architecture adopts SOA for interoperability. For instance, Saleh, et al. [16] proposed a framework for E-government based on SOA using Jordan as a case study. The 
framework is partitioned into client, presentation, application and data layer. According to the authors, the solution allows interoperability between government organs. Similarly, Al-khanjari, et al. [17] proposed an architectural solution for achieving E-government interoperability of independent computing systems. Whereas Al-Rashedi [18] build an architectural model based on SOA and cloud computing to ensure interoperability of multiple E-government services. Although the authors used model approach, the aim is to achieve cooperate E-government systems. Widodo, et al. [19] developed E-government interoperability architecture by use of SOA and Event Driven Architecture (EDA). Gonzalez [20] used SOA to connect cross-cutting services for interoperable Uruguay E-government platform. Also, Kanagwa [21] developed an interoperable E-government framework using SOA model and ontologies and proposed National Enterprise Architecture (NEA) for semantic interoperability. A study by Ma [22] combined SOA and workflow technology to support E-government platform. Although the study focus on processing model joining administration and approval in interoperability of E-government system. Simon et al. [23] proposed an interoperable Hungarian E-government framework by use of web service and SOA as the middleware for implementation.

Baraka \& Madouk [24] proposed SOA-based centralized database framework for Palestine Egovernment. According to the authors, SOA has the capacity of transforming the current centralized database's data integration and interoperability limitations. Similarly, Bonacin et al. [25] designed an e-government interoperability architecture by SOA with SOAP on http communication protocol. The propose models allows citizens involve in decision of services to be provided. The author suggested use of SOA for E-government interoperability. SOA provides interoperable, flexible, and distributed service systems. However, the authors outline on use of http transport in the proposed framework to achieve interoperability and flexibility is misleading. First, messages in SOSE systems are distributed at the application layer not transport layer. Second, the http transport systems are point-to-point connections, where clients read and write into the server. Whereas, SOSE systems are end-to-end connections between service provider and service consumer through a middleware. Overall, the use of SOA solution for interaction with central database is key to interoperability, flexibility, agility and automated distributed systems. Paul and Paul [26] proposed service oriented government enterprise architecture (SOGEA) for E-government interoperability that act as a platform for connected government. The authors analysed the need for E-government interoperability in India and identified reduced IT cost, enable flexibility and optimization as benefits of SOA based E-government implementation. However, high initial implementation cost and resistance from adoption of new technology are some of its bottlenecks.

\section{b) Integration:}

Research on data integration in e-government can be broadly classified into two broad categories; partial integration and the whole E-government platform integration. First, studies by Zhang, et al. [27], Yan \& Zhan-Ping [28] and Utama et al. [29] focused on integrating some aspect of the E-government systems. Zhang, et al. [27] constructed a single model unifying multiple civil aviation aspect of Egovernment. The authors analysed the operations of the integrated civil aviation's application environment in E-government system. Similarly, Yan \& Zhan-Ping [28] used data fusion and SOA to integrate applications in E-government system. The authors tested the solution by integrating departments in education systems of government for quick data response. Whereas, Utama, et al. [29] used SOA for the integration of independent regional government services in Sidoargo Regency. The integration approach is in three phases; database formation, service formation and implementation of service to provide a high speed E-government system.

Next are the studies that focus on integration of the entire E-government system ( [30]; [31]; [32]; [33]; [34]; [35]; [36]; [37]; [38]; [39]; [40]; [41] ). Das, et al. [30] uses open source SOA tools as middleware to integrate heterogeneous services in E-government system. Yau and Guo [31] and Sasono, et al. [38] proposed the use of government service bus (GSB) to handle integration of heterogeneous services in E-government systems. Although, Yau and Guo [31] focused on integration of new and existing services, whereas Sasono, et al. [38] focused on managing government to government (G2G), government to citizens (G2C) and government to business (G2B) services in E-government systems. Yunliang, et al. [32] developed a flexible information management for integrating multiple existing heterogeneous information systems for E-government based on SOA framework. Similarly, Huang and Wang [33] leveraged on the intelligent management capability of Enterprise Service Bus (ESB) for integration of isolated services for information sharing in E-government system. Budiardjo, et al. [34] 
optimized the operations of Indonesian E-government by integrating multiple levels' rules and policies. The authors integrated the services in Zuma E-government Framework (ZEF) to enhance E-government system by SOA and business process management (BPM). Al-Rashedi [35] developed an architectural model to improve service integration in E-government for deployment in private cloud by using SOA technology.

In an effort to unify government services, Mesfin [36] used SOA e-readiness evaluation framework to integrate existing systems. The author discovered that by the use of this approach; legal, government and human resources needs are met. Also, Hodijah, et al. [37] and Almahmoud [41] proposed an SOAbased legacy system integration solution by design model of data exchange between services. The solutions maintained stable load balancing method of the system. To solve the heterogeneous problem of Indonesian government information system, Fajar and Shofi [39] applied the service-oriented design and analysis for an SOA solution to integrate services in Indonesian E-government systems. Similarly, Sofian [40] attempt to transform peer-to-peer system to a single mega public service system and proposed an SOA-based framework for E-government integration portal. The authors uses web service architecture (WSA) to enhance E-government processes. Overall, research has shown that Egovernment integration could be established by use of SOA as a middleware eliminating the cross organizational barriers. Furthermore, the use of SOA technology for integration is imperative for reduced-IT cost, flexible, efficient, agile and loose-coupled E-government system.

c) Modelling:

A study of the relationship between SOA and E-government by Asadi and Rashidi [42] investigated the benefits of implementing E-government by SOA. According to the author, SOA serves as a mediator in E-government system. Generally, research on the conceptual model of service to efficiently align business process with the capabilities of information technologies can be broadly classified into partial ( [43]; [44];[45]; [46]; [36]; [39];[47] ) and comprehensive approach ([48]; [49]; [50]; [51];[52]; [53]; [54]; [55]; [56] and [57] ). Jayawickrama [43] and Najar, et al, [44] proposed an E-complains model by business process execution language (BPEL) to depict the citizen complain process for SOA-based Egovernment system in Sri Lanka. Hariguna [45] used SOA for planning and implementation to solve cost and human resources problems in E-government system. Similarly, Fajar \& Shofi, [39] used service-oriented design approach to propose a conceptual model for Indonesian E-government travelling system. Whereas Bao \& Zhao [46] applied the bottom-up approach starting from coding of the supporting modules' logic to develop call services in SOA-based E-government system. Mesfin, et al. [36] evaluated the E-readiness by a flexible and scalable model of E-government framework for Ethiopia. Also, Suzuk \&Suzuk [47] proposed an architectural model for transport management system in E-government system by SOA. The author used large cargo as a case study and discovered that the model enhanced data validation and provides quicker interaction as well as cheaper logistic.

In an effort to comprehensively improve E-government services to citizens, Najebpour, et al. [48] used architectural model of government concepts to enhance citizens' satisfaction with communications in SOA-based E-government systems. Also, Kileo \& Bograd [50] used model to analyse the relationship between government to government $(\mathrm{G} 2 \mathrm{G})$, government to business $(\mathrm{G} 2 \mathrm{~B})$ and government to citizens (G2C) components of E-government systems. The authors presented a layered decomposition model for SOA-based E-government system. Similarly, Nogo \& Macan [51] developed service modules for government to government $(\mathrm{G} 2 \mathrm{G})$, government to business $(\mathrm{G} 2 \mathrm{~B})$ and government to citizens $(\mathrm{G} 2 \mathrm{C})$ service provision to establish data exchange for SOA-based E-government system for Bosnia Herzegovina. Whereas Kim, et al. [52] analysed the adoption ideologies for the application of SOAbased E-government implementation in Japan and Dico [53] analysed current E-government models to identify novel challenges in SOA-based E-government. The author discussed on enterprise architectural model of governments and highlights the challenges in E-government implementation by SOA. By using the same approach, Sedeno, et al, [54] analysed the vital context of business administration of public service in E-government system. The author presented a model for practical application of SOA in public administration.

Other comprehensive modelling approach by Ray \& Debnah [49] introduced the use of agile and extreme programming principles for implementation of SOA-based E-government systems. This approach differs from that of Gitau [57] who developed a model of Kenyan E-citizen application for SOA-based E-government by survey and service-oriented modelling architecture (SOMA). An approach by Barakat and El-Beqqati [55] proposed a database design for flexible E-government system 
by Extract Transfer Load (ETL) process and SOA. While Nakonechnyi, and Kolisnichenko [56] analysed information flow and technological infrastructure to propose user-orientation model for effective collaboration of all participant in SOA-based E-government system of Ukraine. Finally, a comprehensive approach by Qusef, et al. [58] proposed an SOA-based E-government implementation model with an overview of the required digital e-service and partial interaction. Overall, substantial number of research focused on partial or comprehensive modelling of business process for efficient adoption of SOSE-based E-government system. However, research in this aspect is not yet exhausted, particularly with the evolutionary nature of governance.

d) Security:

Enforcing security across E-government systems is challenging in view of dynamic and heterogeneous nature of its communication network. Information security vulnerability in E-government system ranges from identification, authentication, access control, data integrity to confidentiality issues. Despite the ever-increasing network security threats, little research attention is directed toward protection of Egovernment system. An attempt by El-keffas and Fouad [59] to enhance data integrity in E-government by using SOA as the middleware between reusable independent applications of government agencies. Whereas Zhiguang and Ting [60] studied SOA integration of E-government and proposed an identity authentication model for the system. Security is an important aspect of service systems to achieve a successful SOSE-based E-government system. As such, further research should be conducted in this area for the protection of both citizens' and governments' information.

\subsection{Research Method:}

According to Kitchenham, et al. [61], systematic literature review is a process of identifying, selecting, assessing, analyzing and interpreting all available literature on a particular area of investigation. Systematic literature review is a powerful literature review method because it uses a predefined review protocol which results in thorough, robust, and fair review.

\subsubsection{Review Protocol:}

The review protocol guided the research process from formulation of research questions, search strategy, inclusion and exclusion criteria, quality assurance, and study selection to data extraction on primary studies

\section{a) Research Questions}

RQ1: What is the research distribution on SOSE-Based E-government system from 2010 to 2021 ?

RQ2: Which aspect of SOSE-Based E-government system requires further research?

\section{b) Search Strategy}

The search was conducted by use of key terms of the research questions and synonyms. These terms were connected by Boolean operators (AND, OR) in order to retrieve all relevant articles. The Boolean "OR" was used to construct search strings with similar meaning. Whereas, the Boolean "AND" was used to connect the distinct parts of the search string. Consequently, the search string is:

$<$ SOSE or SOA or SOC or SBA or "Service-Oriented" or "Service-Based" or "Service-Centric" or "Service System" or "Service System Engineering"> AND < E-Government or "Digital Government" or "Electronic Government" or "Online Government" >

\section{c) Inclusion and Exclusion Criteria}

\section{Inclusion Criteria}

i. A primary study must be on SOSE-based E-government System.

ii. A primary study must be published within 2010 and 2021.

iii. The research direction of the primary study must be relevant to the research questions.

iv. A primary study must be written in or can be translated to English language.

\section{Exclusion Criteria}

i. All primary studies that are not related to the research questions in anyway.

ii. All primary studies published before 2010 and after 2021.

iii. All primary studies written in other language apart from English language without translation.

d) Study Selection

All primary studies that satisfied the inclusion criteria was selected for further scrutiny. However, this review covered primary studies from 2010 to 2021 only. Furthermore, the studies that is not written in English language and all effort to obtain its translation in English language failed was excluded. 
e) Quality Assurance

The collection of primary studies from 2010 to 2021 that are related to SOSE-based E-government system were subjected to scrutiny. Subsequent to screening the studies by the inclusion and exclusion criteria to remove irrelevant articles, suitable once were saved in Mandele Reference Manager. Further scrutiny was conducted to remove duplicate as well as ascertain the quality and relevance of gathered articles in answering the research questions.

\section{f) Data Extraction}

An outline of the data extraction procedure is as follows:

$>$ Examine selected primary studies' Title, Abstract and Keywords to discard unrelated articles.

$>$ Retrieve the full-text of relevant articles for further evaluation.

$>$ Critically evaluate primary studies' eligibility.

$>$ Extract relevant data required to answer the research questions of this study.

$>$ Record the extracted data on the Data Extraction Form in Table 1.

Table 1: Data Extraction Form

\begin{tabular}{|l|l|}
\hline Publication Date & \\
\hline Author & \\
\hline Title & \\
\hline Research Direction & \\
\hline
\end{tabular}

\subsubsection{Review Conduction Process}

In compliance with the review protocol, the conduct of the literature can be depicted by the flow chart on figure 1 .

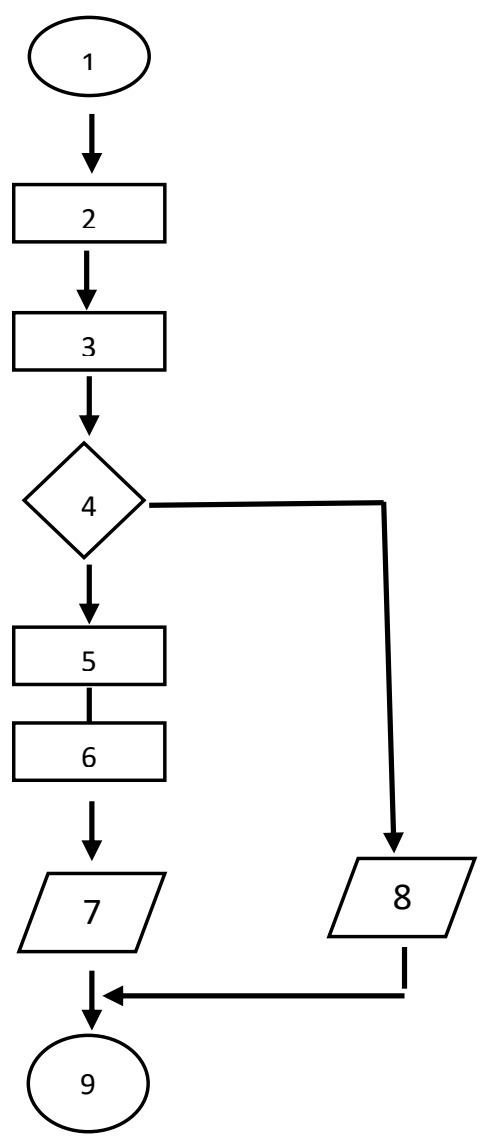

\section{Detail description}

1. Start

2. Search using Search string

3. Read Title, Abstract \& Keywords of all potential Studies

4. Is primary studies relevant?

5. If yes, then extract full text

6. Critically Evaluate to Text

7. Record its Direction

8. Exclude

9. Stop

Fig. 1: Flow Chart for Review Process 
First, search for potential primary studies by use of the search string. Second, then read the title, abstract and keywords of potential primary studies to evaluate its relevance to the research questions, where irrelevant studies was excluded. Third, relevant studies was extracted for evaluation. Fourth, all relevant studies was evaluated critically to identify its research direction. Finally, the research direction of each selected paper was recorded.

\section{RESULTS AND DISCUSSIONS :}

\subsection{Data Analysis}

Data analysis involve summarizing by classifying the data gathered from selected primary studies. The analysis of data collected from this study is classified into two categories in line with the research questions. First, selected primary studies were classified according to the year of publication as shown in table 2.

Table 2: No of Publications per Year

\begin{tabular}{|l|l|l|l|l|l|l|l|l|l|l|l|l|l|}
\hline Year & $\begin{array}{l}201 \\
0\end{array}$ & $\begin{array}{l}201 \\
1\end{array}$ & $\begin{array}{l}201 \\
2\end{array}$ & $\begin{array}{l}201 \\
3\end{array}$ & $\begin{array}{l}201 \\
4\end{array}$ & $\begin{array}{l}201 \\
5\end{array}$ & $\begin{array}{l}201 \\
6\end{array}$ & $\begin{array}{l}201 \\
7\end{array}$ & $\begin{array}{l}201 \\
8\end{array}$ & $\begin{array}{l}201 \\
9\end{array}$ & $\begin{array}{l}202 \\
0\end{array}$ & $\begin{array}{l}202 \\
1\end{array}$ & $\begin{array}{l}\text { Tota } \\
1\end{array}$ \\
\hline $\begin{array}{l}\text { No of } \\
\text { Publicatio } \\
\text { n }\end{array}$ & 10 & 4 & 7 & 4 & 7 & 4 & 2 & 6 & 3 & 5 & 6 & 3 & 61 \\
\hline
\end{tabular}

Second, after evaluation, articles were classified according to identified research direction of the primary studies as shown in table 3 .

Table 3: No of Publications per Research Direction

\begin{tabular}{|l|l|}
\hline $\begin{array}{l}\text { Research } \\
\text { Direction }\end{array}$ & No of Publication \\
\hline Integration & $\mathbf{1 7}$ \\
\hline Interoperability & $\mathbf{2 2}$ \\
\hline Modelling & $\mathbf{2 0}$ \\
\hline Security & $\mathbf{2}$ \\
\hline Total & $\mathbf{6 1}$ \\
\hline
\end{tabular}

\subsection{Reporting and Discussion}

This section provide the report of the review results presented in charts followed by a precise discussion on each chart as follows.

a) Research Distribution from 2010 to 2020

RQ1: What is the research distribution on SOSE-Based E-government system from 2010 to 2021

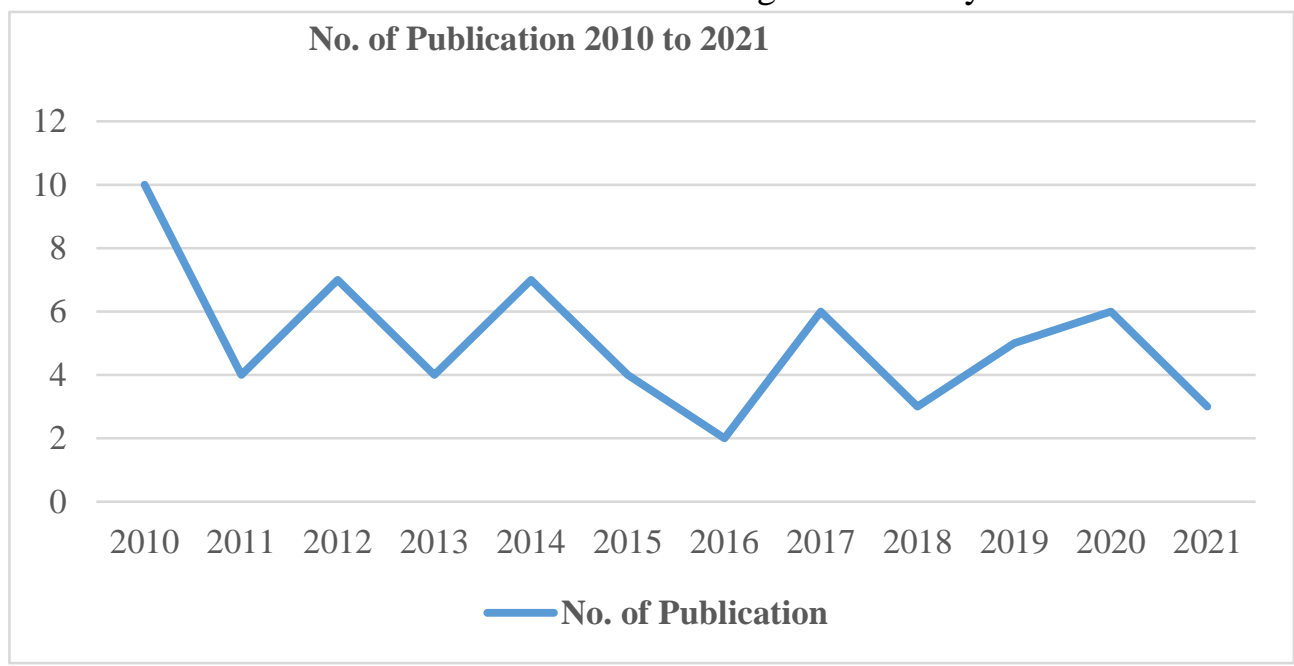

Fig. 2: Graph of Publications from 2010 to 2021 
The graph on figure 2 shows the number of publications made in the reviewed period of twelve (12) years from 2010 to 2021. First, the highest number of publications of 10 was made in 2010, it then drops to 4 in 2011. This followed by double fluctuations of rises to 7 and drops 4 between 2012 and 2015 . Then drops to its lowest number 2 in 2016 and rose to 6 in 2017. The number of publication drops back to 3 in 2018 and rises steadily up for two consecutive years to 6 in 2020. Finally, it drops back to 3 in 2021. In conclusion, the lowest number of publications was 2 made in 2016. Whereas the highest number of publication was in the year 2010 with 10 publications.

b) Research Classification

RQ2: Which aspect of SOSE-Based E-government system requires further research?

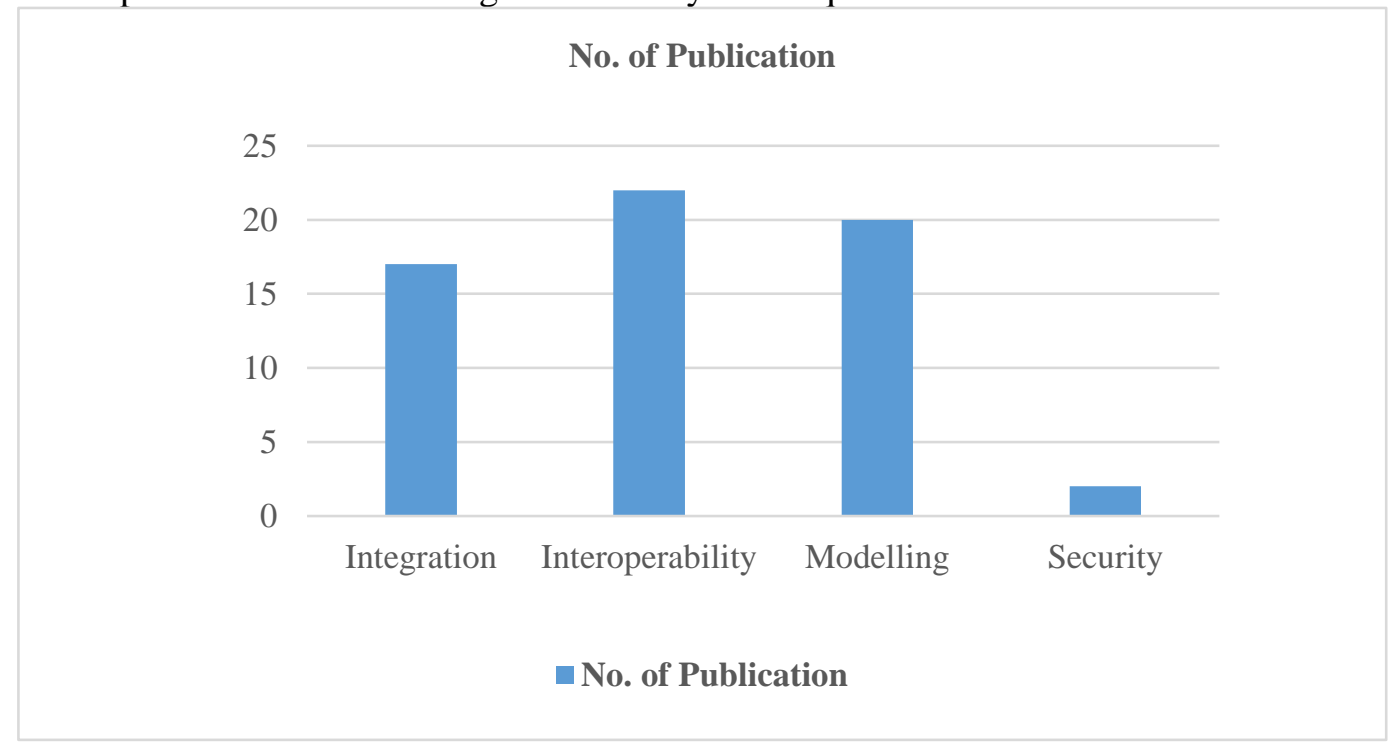

Fig. 3: Chart for Publications per Research Direction

The bar chart on figure 3 illustrates the number of publications for each research direction. Remarkably, interoperability recorded highest attention by researchers with 22 number of publications. The next two research focuses that recorded higher attention are modelling and integration with 20 and 17 number of publications respectively. Security is the research area that received least attention in the reviewed period. Consequently, information security is the aspect of SOSE-based E-government system that requires further research.

\section{CONCLUSION AND RECOMMENDATIONS :}

Research has shown that use of SOA for integration provides flexible and responsive E-government system. This approach transforms independent systems and applications into highly efficient, robust, loosely couple, agile, flexible and reusable E-government system. SOA is an essential technology for integration of systems' belonging to governments' ministries, departments and agencies (MDA) with business and other levels of government for a standard interoperable E-government systems. Although, research has shown that interoperability could be achieved by integration of systems. This review discovered that interoperability of independent systems and applications can be established by SOSE principles without the need for integration. SOSE technology facilitates interoperability among different isolated systems and applications for flexible and loosely coupled E-government system.

Modelling involves making a representation of real world business logic and data for translation into programme to behave like the real life system in order to accurately close the gap between business analysis and information technology (IT). This study discovered that SOSE approach is a systematic and flexible way of modelling services for E-government system. However, in view of the heterogeneous and continuous change in business operations of governments and businesses, further research is required toward effective modelling and designing for complex E-government system. Finally, information security received less attention in the reviewed period. Despite an increase in awareness on SOSE approach for effective E-government development. However, concern caused by fear of malicious acts that might attack or shutdown E-government system is a serious concern. Consequently, it is recommended that further research be conducted toward SOSE security for protection of E-government systems. 


\section{REFERENCES :}

[1] Sá, F., Rocha, Á., Gonçalves, J., \& Cota, M. P. (2017). Model for the Quality of Local Government Online Services. Telematics and Informatics. 34(5), 413-421.

Google Scholar X

[2] Lenhart, A., Purcell, K., Smith, A., \& Zickuhr, K. (2010). Social Media \& Mobile Internet Use among Teens and Young Adults. Millennials. Pew internet \& American life project. 2010(1), 1-37. Google Scholar X

[3] Behara, G. K., Varre, V. V., \& Rao, M. (2009). Service Oriented Architecture for EGovernance. Bptrends, October, 2009(1), 1-13.

Google Scholar ${ }^{\top}$

[4] Smitha, K. K., Thomas, T., \& Chitharanjan, K. (2012) Cloud Based E-governance System: A Survey. Procedia Engineering, 38(1), 3816-3823

Google Scholar $X^{\top}$

[5] Tripathi, A., \& Parihar, B. (2011). E-Governance Challenges and Cloud Benefits. In 2011 IEEE International Conference on Computer Science and Automation Engineering. IEEE June, 2011(1), 351-354.

Google Scholar X

[6] Mosa, A., El-Bakry, H. M., Abd El-Razek, S. M., \& Hasan, S. Q. (2016). A Proposed EGovernment Framework Based on Cloud Service Architecture. International Journal of Electronics and Information Engineering. 5(2), 93-104.

Google Scholar X

[7] Alshomrani, S., \& Qamar, S. (2013). Cloud Based E-Government: Benefits and Challenges. International Journal of Multidisciplinary Sciences and Engineering, 4(6), 1-7.

Google Scholar X

[8] El Benany, M. M., \& El Beqqali, O. (2015). SOA Based E-Government Interoperability. In 2015 IEEE/ACS 12th International Conference of Computer Systems and Applications (AICCSA), IEEE. 12(1), 1-2. Google Scholar ${ }^{7}$

[9] Das, R., Patra, M., \& Misro, A. (2010). Open Source SOA For E-Governance. In 7th International Conference on E-Governance ICEG. 7(1). 1-10

Google Scholar $X^{7}$

[10] Alghamdi, B., Potter, L. E., \& Drew, S. (2016). Identifying Best Practices in Organisational SOA Governance Adoption: Case Study of Saudi Arabia's E-Government Programme. In PACIS. 365(1), $1-15$

Google Scholar $\not$

[11]Sedek, K. A., Omar, M. A., \& Sulaiman, S. (2012). Interoperable SOA-based Architecture for Egovernment Portal. In 2012 IEEE Conference on Open Systems. IEEE, 2012(1), 1-6. Google Scholar $X^{7}$

[12] Madoukh, S., \& Baraka, R. A. (2014). SOA-Based e-Government Data Integration. International Arab Journal. E-Technology. 3(3), 138-145.

Google Scholar $x^{7}$

[13] Paul, A., \& Paul, V. A. (2014). Framework for E-government Interoperability in Indian Perspective. International Journal of Computer Information Systems and Industrial Management Applications, 6(1), 582-591.

Google Scholar $X^{\top}$

[14] AlHajri, A., Al-Khanjari, Z., Kraiem, N., \& Al-Jamoussi, Y. (2017). Enhanced E-Government Integration Framework for Higher Interoperability in e-Government Initiatives. 2017 IEEE 
International Conference On Intelligent Computing, Instrumentation And Control Technologies. 17(1), 1831-1846

Google Scholar X

[15] Sedek, K. A., Sulaiman, S., \& Omar, M. A. (2011). A systematic Literature Review of Interoperable Architecture For E-Government Portals. In 2011 Malaysian Conference in Software Engineering. IEEE. December, 11(1). 82-87.

Google Scholar $X^{\top}$

[16] Saleh, Z. I., Obeidat, R. A. and Khamayseh, Y. A. (2013). Framework for an E-government Based on Service Oriented Architecture for Jordan. International Journal of Information Engineering \& Electronic Business, 5(3), 1-10.

Google Scholar X

[17] Al-Khanjari, Z., Al-Hosni, N., \& Kraiem, N. (2014). Developing a Service Oriented E-Government Architecture Towards Achieving E-Government Interoperability. International Journal of Software Engineering and Its Applications. 8(5), 29-42

Google Scholar $x^{7}$

[18] Al-Rashedi, A. A. (2014). E-government Based On Cloud Computing And Service-Oriented Architecture. International Journal of Computer and Electrical Engineering. 6(3), 201-206.

Google Scholar $x^{\top}$

[19] Widodo, A. P., Istiyanto, J. E., Wardoyo, R., \& Santoso, P. (2013). E-Government Interoperability Framework Based on a Real Time Architecture. International Journal of Computer Science Issues (IJCSI). 10(1), 169-177.

Google Scholar $X^{7}$

[20] González, L., Ruggia, R., Abin, J., Llambías, G., Sosa, R., Rienzi, B., ... \& Álvarez, F. A. (2012). Service-Oriented Integration Platform to Support a Joined-up E-government Approach: The Uruguayan Experience. In International Conference on Electronic Government and the Information Systems Perspective. Springer, Berlin, Heidelberg. September. 7452(1), 140-154.

Google Scholar X

[21] Kanagwa, B., Nakatumba-Nabende, J., Mugwanya, R., Kahiigi, E. K., \& Ngabirano, S. (2017). Towards an Interoperability E-Government Framework for Uganda. InInternational Conference on e-Infrastructure and e-Services for Developing Countries. Springer, Cham. 250(1), 16-28. Google Scholar X

[22] Ma, H. A. (2010). Service-Oriented E-government Support Platform for Integration of Application and Data. In 2010 Second International Conference on Information Technology and Computer Science. IEEE. 1(1), 398-401.

Google Scholar $X^{7}$

[23] Simon, B., László, Z., Goldschmidt, B., Kondorosi, K., Risztics, P., \& Bacsa, L. (2010). Evaluation of WS-* Standards Based Interoperability of SOA Products for The Hungarian E-Government Infrastructure. In E-Government, E-Services and Global Processes. Springer, Berlin, Heidelberg. 334(1), 19-31.

Google Scholar $x^{7}$

[24] Baraka, R. S., \& Madoukh, S. M. A. (2012). Conceptual SOA-based Framework for E-Government Central Database. In 2012 International Conference on Computer, Information and Telecommunication Systems (CITS) IEEE. 12(1), 1-5.

Google Scholar X

[25] Bonacin, R., Melo, A. M., Simoni, C. A., \& Baranauskas, M. C. C. (2010). Accessibility and Interoperability in E-government Systems: Outlining an Inclusive Development Process. Universal Access in the Information Society. 9(1), 17-33.

Google Scholar X 
[26] Paul, A., \& Paul, V. A. (2014). Framework for E-Government Interoperability in Indian Perspective. International Journal of Computer Information Systems and Industrial Management Applications. 6(1), 582-591.

Google Scholar $X^{7}$

[27] Zhang, X., Wei, J., \& Jing, X. (2011). The Design and Implementation of Civil Aviation Electronic Government System Based on SOA. In 2011 International Conference on Business Management and Electronic Information. IEEE. 4(1), 159-162.

$\underline{\text { Google Scholar X }}$

[28] Yan-jun, Q.I., Zhan-ping, D.A.N. and Center, N. (2015). Data Exchange and Integration Mechanism of E-government Based on SOA-Study about Education E-government. Computer Technology and Development. 38(11), 3816 - 3823.

Google Scholar $x^{\top}$

[29] Utama, A. P., Asmara, R., \& Hasim, J. A. N. (2019). E-Government Integration of Sidoarjo Regency using Service Oriented Architecture (SOA). IJNMT International Journal of New Media Technology, 6(2), 109-115.

Google Scholar X

[30] Das, R., M. Patra, and A. Misro. (2010). "Open Source SOA for E-Governance.” 7th International Conference on E-Governance ICEG. 7(1), 1-10.

Google Scholar $X^{\top}$

[31] Yan, Pei, and Jiao Guo. (2010). "Researching and Designing the Architecture of E-government Based on SOA." 2010 International Conference on E-Business and E-Government. IEEE. 137(1), 512-515.

Google Scholar X

[32] Yunliang, J., Xiongtao, Z., Qing, S., Jing, F., \& Ning, Z. (2010). "Design of E-Government Information Management Platform Based On SOA Framework." 2010 First International Conference on Networking and Distributed Computing. IEEE, 42(1), 165-169

Google Scholar X

[33] Huang, W. L., \& Wang, F. (2012). Research of E-government System Architecture Based on SOAESB. In Advanced Materials Research. Trans Tech Publications Ltd. 479(1), 1137-1140.

Google Scholar X

[34] Budiardjo, E. K., Fajar, A. N., \& Hasibuan, Z. A. (2013). ZEF Framework for E-Government Applications: Featuring SOA \& BPM Alignment. International Journal Computer Theory and Engineering. 5(2), 366-376.

Google Scholar X

[35] Al-Rashedi, A. A. (2014). "E-government Based on Cloud Computing and Service-Oriented Architecture." International Journal of Computer and Electrical Engineering, 6(3), 201 -206. Google Scholar $x^{\top}$

[36] Mesfin, G., Grønli, T. M., Ghinea, G., \& Younas, M. (2017). Adopting SOA in Public Service Provision. In International Conference on Mobile Web and Information Systems. Springer, Cham. 10486(1), 279-289.

Google Scholar $x^{7}$

[37] Hodijah, A., Sundari, S., \& Nugraha, A. C. (2018). Applying TOGAF for E-Government Implementation Based on Service Oriented Architecture Methodology Towards Good Government Governance. In Journal of Physics: Conference Series. IOP Publishing. 1013(1), 1-8.

Google Scholar X

[38] Sasono, D. S., Setyohadi, D. B., \& Santoso, A. J. (2018). E-Government Integration Based on SOA for Supporting Sleman Smart Regency (A Case Study of Sleman Regency, Special Region of Yogyakarta). 18(1), 360-366

Google Scholar X 
[39] Fajar, A. N. and Shofi, I. M. (2019). "Service Oriented Design for Indonesian E-Government System Using SOA." IOP Conference Series: Materials Science and Engineering. IOP Publishing, $598(1), 1-5$.

Google Scholar $X^{7}$

[40] Sofian, A. R. (2019). "Designing SOA-based BATAN Public Services with Restful Web Service." 2019 International Conference on ICT for Smart Society (ICISS), IEEE. 7(1), 1-6.

Google Scholar X

[41] Almahmoud, A. A. (2020). E-Services Integration Framework Based on SOA. In Proceedings of the 12th International Conference on Information Management and Engineering. 16(1), 1-6.

Google Scholar X

[42] Asadi J, \& Rashidi H. (2012). E-government with Service Oriented Architecture. International Journal of Advanced Research in Computer Science. 3(4), 91-93.

Google Scholar $x^{\top}$

[43] Jayawickrama, G. I. U. (2021). Customer Complaint Management System using SOA. University of Columbia digital library (Doctoral dissertation). 1(1), 1-93

Google Scholar X

[44] Najar, A. S., Hassan A. A. and Navid A. (2010). "The application of service-oriented architecture in e-complaint system." 2010 Second International Conference on Communication Software and Networks. IEEE, 107(1), 280-283.

Google Scholar $X^{7}$

[45] Hariguna, T. (2011). Prototype Cloud Computing for E-Government in Indonesia. International Journal of Engineering \& Technology IJETIJENS. 11(6), 131-134.

Google Scholar X

[46] Bao, F. and Fengzhi Z. (2011). Study on the E-government Call Center System Based on SOA. Computer and Information Science, 4(4), 120-122.

Google Scholar X

[47] Suzuki, T., \& Suzuki, L. (2020). On the Benefit of 3-tier SOA Architecture Promoting Information Sharing Among TMS Systems and Brazilian E-Government Web Services: A CT-e Case Study. 13047(1), 1-14.

Google Scholar $x^{7}$

[48] Nayebpour, A., Bahareh A. and Hassan R. (2014). Evaluation of Satisfaction of Human Resources in Service-Oriented e-Government (SOA-Gov). Quarterly Journal of Logistics \& Human Resources Management. 1393(32), 63-82.

Google Scholar X

[49] Roy, S., \& Debnath, M. K. (2010). Designing SOA Based E-governance System Using EXtreme Programming Methodology for Developing Countries. In 2010 2nd International Conference on Software Technology and Engineering IEEE. 2(1), 282-277.

Google Scholar X

[50] Kileo, M. V., \& Bograd, A. (2010). E-Government Based on Service Architecture. 7th SC@ RUG 2009-2010 proceedings: Rijksuniversiteit Groningen, 7(1), 29-33.

Google Scholar $X^{\top}$

[51] Nogo, S., \& Macan, S. (2012). SOA Based E-Government System In Bosnia and Herzegovina. International Journal on Information Technologies \& Security. 4(2), 73-90.

Google Scholar X

[52] Kim, H. J., Lee, H. S., \& Jung, Y. G. (2017). SOA-based Web Service Application and Analysisforcused to Japan Electronic Government. The Journal of the Convergence on Culture Technology. $3(1), 25-28$.

Google Scholar X 
[53] Dico, A. S. (2012). Towards whole-of-government EA with TOGAF and SOA. Enterprise Architecture for Connected E-Government: Practices and Innovations. IGI Global, 7(1), 177-204. Google Scholar $X^{\top}$

[54] Sedeño, J., Salinas, C. J. T., Escalona, M. J., \& Mejías, M. (2014). An Approach to Transform Public Administration into SOA-based Organizations. In WEBIST 2014: 10th International Conference on Web Information Systems and Technologies. ScitePress Digital Library. 10(1), 135142.

$\underline{\text { Google Scholar } \not}$

[55] Barakat O, \& El-Beqqali O. (2020). Business Intelligence and SOA Based Architecture for EGovernment System Interoperability. In Proceedings of the 13th International Conference on Intelligent Systems: Theories and Applications. 13(1), 1-5.

$\underline{\text { Google Scholar X }}$

[56] Nakonechnyi, A., \& Kolisnichenko, N. (2020). Service-Oriented Architecture of E-Government: Characteristics of the Anglo-American Model and Peculiarities of its Implementation in Ukraine. Public administration and local government. 47(4), 39-48.

Google Scholar X

[57] Gitau, J. K. (2016). Service Oriented Architecture Model for Integration Of E-Government Systems In Kenya. Diss. University of Nairobi, 37(17), 1-68.

Google Scholar X

[58] Qusef, A., Abdallah A. and Adnan S. (2021). Comprehensive Approach to Implement EGovernment Backend in Jordan Using Service-Oriented Architecture. International Journal of Software Innovation (IJSI). 9(2), 122-135.

Google Scholar X

[59] Elkaffas, S. M., \& Fouad, H. S. (2013). Optimizing Rules Sharing System in e-Government Using Service-Oriented Architecture: A Case Study in Egypt. In 2013 23rd International Conference on Computer Theory and Applications (ICCTA). IEEE. 23(1), 122-127.

Google Scholar X

[60] Zhiguang W, \& Ting Y. (2010). A Security E-Government Model Based On Service-Oriented Architecture. In 2010 International Conference on E-Health Networking Digital Ecosystems and Technologies (EDT) IEEE. 17(1), 280-283.

Google Scholar X

[61] Kitchenham, B., Brereton, O. P., Budgen, D., Turner, M., Bailey, J. and Linkman, S. (2009). Systematic Literature Reviews in Software Engineering-A Systematic Literature Review. Information and Software Technology. 51(1), 7-15.

Google Scholar $x^{\top}$ 